\title{
5. Does formalization enhance institutional effectiveness?
}

\section{THE ISSUE OF FORMALIZATION}

Mainstream thinking about governance generally takes it for granted that it is desirable to formalize governance systems by grounding them in the provisions of legally binding instruments. Especially pronounced in the analyses of those whose thinking reflects Western conceptions of the rule of law, this premise underlies much of the work of social scientists as well as legal scholars who have contributed to the remarkable growth of knowledge regarding the creation and performance of the regimes or, more broadly, institutions that have developed in recent decades to address needs for governance in a range of areas, including environmental protection, trade, arms control, and even human rights (Chayes and Chayes 1995; Mitchell 2003; Biermann 2014). On this account, informal arrangements are often lumped together in a somewhat ill-defined category labeled soft law (Abbott and Snidal 2000; Chinkin 2008). The standard view regarding such arrangements is that they are somehow underdeveloped. They may constitute a good beginning in specific cases, but we should make every effort to nurture them so that they can evolve into formalized or hard-law arrangements at the earliest opportunity.

What is the basis for this clear preference for formalized governance systems? Few analysts offer explicit or easily comprehensible answers to this question; the preference for formalized arrangements may be simply a form of received wisdom or owe as much to cultural predispositions as it does to any solid evidence regarding the superior performance of hard-law systems. In the final analysis, however, the preference for formalized arrangements must rest on the presumption - whether clearly articulated or convincingly argued - that arrangements grounded in legally binding instruments will prove more effective or more successful than informal arrangements in addressing needs for governance arising in human societies. Subjects of governance systems are simply more inclined to take seriously prescriptions that have the force of law behind them or develop a habit of obedience in response to hard laws, adapting or adjusting their behavior accordingly (Hart 1961). 
Is the preference for formalized arrangements persuasive? Or are there conditions under which informal arrangements are preferable, though formalized arrangements may make more sense under other circumstances (Lipson 1991)? In this chapter, I address these questions, drawing on recent experience with governance systems in the Arctic as a source of empirical evidence. Over the last 30 years, the Arctic has become a lively arena for the development of innovative arrangements dealing with needs for governance at the international or transnational level. Some of these governance systems have been set up at the outset as legally binding arrangements. Others have begun life as informal arrangements and developed over time into formalized arrangements. Still others take the form of informal arrangements that have shown little sign of developing into anything more formalized. The Arctic thus provides a rich vein of material to mine as a basis for thinking about the relationship between (in)formality and the capacity of the resultant arrangements to deal effectively with particular needs for governance.

I tackle this subject in several steps. The next section deals with matters of terminology, clarifying the distinction between formal and informal arrangements in the interests of avoiding confusion arising from terminological misunderstandings. I then provide a brief introduction to recent institutional innovations in Arctic affairs, highlighting the development of the Arctic Council but making it clear that a range of other innovations have arisen in the Arctic during the same era. This provides a point of departure for an analysis of the central question: does formalization yield better results than those arising from the operation of informal institutions? I address this question through an assessment of the performance of the Arctic cases. My conclusion is that we need to think carefully about conditions under which formal arrangements and informal arrangements are likely to thrive rather than adhering to the conventional preference for formalized governance systems without regard to relevant conditions.

\section{CLARIFYING KEY CONCEPTS}

Formalized governance systems are arrangements that are rooted in the provisions of legally binding instruments. Although this may seem straightforward, several complications are worth noting explicitly. The procedures that individual members of international society use to ratify or otherwise accede to legally binding instruments vary considerably. Consider the case of the United States for purposes of illustration. The gold standard occurs when the US Senate ratifies an agreement and Congress passes implementing legislation to ensure that the agreement's provisions make the transition from paper to practice. The Montreal Protocol on Substances that Deplete the Ozone Layer is a prominent example (Bryner 1995). Short of this, the US Senate may ratify 
an agreement, but ratification is not followed by the passage of implementing legislation. Responsible agencies are left to pursue implementation on the basis of preexisting authority allowing them to engage in the required activities. The Agreement on the Conservation of Polar Bears is a case in point (Fikkan et al. 1993). In still other cases, the United States accepts an agreement as legally binding through executive action without submitting the agreement to the Senate for ratification. The 2015 Paris Climate Agreement is a prominent example (Wirth 2016). Beyond this, there are cases in which the United States and other members of international society treat certain arrangements as having the status of customary international law, even though they have not ratified agreements establishing such arrangements or otherwise taken formal steps to accept these arrangements as legally binding. For example, the United States takes the view that many (but not all) of the provisions of the $1982 \mathrm{UN}$ Convention on the Law of the Sea have acquired the force of law, despite the fact that the US Senate has rebuffed presidential requests to ratify the convention on several occasions.

These differences are clearly significant. There is good reason to expect governance systems that meet the gold standard to carry more weight when it comes to guiding the behavior of both subjects and administrators than arrangements that feature lesser commitments. The ease with which the Trump Administration was able to abandon US participation in the Paris Climate Agreement is a clear example of the weakness of commitments that do not involve formal ratification. For purposes of this analysis, nevertheless, I will treat those arrangements that fit into one or another of the categories described in the preceding paragraph as formalized governance systems.

This makes it tempting simply to treat informal arrangements as a residual category including all those governance systems that do not belong to one or another of these categories of formalized systems. But this would be a mistake for several reasons. Social scientists have long recognized that some institutions arise spontaneously or in the absence of intentional initiatives on the part of individuals or groups. They take the form of spontaneous or self-generating social practices that are acknowledged at the level of behavior and that serve important steering functions in a variety of settings (Hayek 1973). Such arrangements are the norm in many smallscale traditional societies that lack a government in the modern sense of the term (Ostrom 1990). But they are not limited to such settings. Although they may be subject to a growing collection of regulatory arrangements over the course of time, markets are social institutions that emerge spontaneously in a variety of settings. Nor are such self-generating arrangements absent at the international level. Influential codes of conduct, for example, thrive in this setting, even when they are not products of intentional initiatives, much less articulated in the form of formal agreements. There is much to be said about the roles that spontaneous insti- 
tutions play in a variety of settings; a serious body of knowledge about such matters has arisen within several of the social sciences. Nevertheless, these spontaneous arrangements are not the subject of this analysis. Rather, I treat informal governance systems as arrangements that are the results of intentional initiatives, but that are not grounded in legally binding instruments.

The resultant universe of informal governance systems encompasses a number of differentiable types of arrangements. In the Arctic, recent practice has emphasized arrangements established under the terms of non-legally binding ministerial declarations. The 1996 Ottawa Declaration on the Establishment of the Arctic Council is a prominent example (Smieszek 2019). But this is by no means the only sort of arrangement to be considered under the rubric of informal systems. Other informal arrangements involve important roles for simple agreements not articulated in high-profile much less legally binding documents, guidelines that are not legally binding, informal codes of conduct, and strategic plans providing guidance regarding well-defined issues, though they are not governance systems in their own right. There is experience with all these mechanisms in the recent history of the Arctic. In this chapter, I use the phrase informal governance systems to encompass the set of arrangements that share the property of being intentional without being formalized in legally binding instruments. My central concern is to compare and contrast formalized arrangements and informal arrangements in terms of their performance in addressing a variety of needs for governance.

\section{AN INTRODUCTION TO ARCTIC GOVERNANCE}

Located on the front line of the confrontation between the Soviet Union and the United States during the Cold War, the Arctic offered few opportunities to put in place international regimes designed to produce cooperative responses to needs for governance (Osherenko and Young 1989). But the close of the Cold War and the subsequent collapse of the Soviet Union at the end of 1991 released energy to tackle a variety of transboundary issues of interest to varying combinations of states. Perhaps the most important observation about the resultant pattern of international cooperation is that it does not rest on a comprehensive constitutive foundation. In the Arctic, there is no analogue to the 1959 Antarctic Treaty to provide a constitutive framework within which to develop a variety of operational regimes allowing different combinations of actors to address a variety of specific issues. Despite recurrent calls emanating from a number of quarters for the development of an Arctic Treaty, there is no prospect that such an agreement will emerge during the foreseeable future. What we have in the Arctic, then, is a governance or regime complex composed of a number of discrete elements that focus individually on matters of interest to specific sets of actors and that, taken together, reflect a range of 
perspectives on the types of arrangements most appropriate to address specific needs for governance arising in this region (Alter and Raustiala 2018). Table 5.1 provides a comprehensive listing of the resultant universe of Arctic cases. There is no shortage of arrangements dealing with Arctic issues grounded in legally binding instruments. Surprisingly, several of these arrangements emerged during the course of the Cold War. In 1973, for example, the five range states (Canada, Denmark, Norway, the Soviet Union, and the United States) negotiated the legally binding Agreement on the Conservation of Polar Bears. And in 1976, the Soviet Union and the United States agreed on the terms of a bilateral convention on the conservation of migratory birds and their environment. The pace regarding the creation of legally binding Arctic regimes has accelerated during the ensuing years (Byers 2013). In 1994, China, Japan, Korea, Poland, Russia, and the United States agreed on the terms of the Convention on the Conservation and Management of the Pollock Resources of the Central Bering Sea. More recently, the eight Arctic states have entered into a series of legally binding arrangements whose terms have been negotiated under the auspices of the Arctic Council. These include the 2011 agreement on search and rescue in the Arctic, the 2013 agreement on marine oil spill preparedness and response, and the 2017 agreement on the enhancement of cooperation in scientific research. Notably, the resultant collection of agreements includes cases exemplifying the principal subsets of formalized governance systems I identified in the preceding section.

Recent experience in the Arctic also encompasses cases in which arrangements launched initially either as informal regimes or as a mix of formal and informal arrangements have developed into broader formalized governance systems over the course of time. Starting in the 1970s, Norway and the Soviet Union (now the Russian Federation) developed step-by-step a bilateral regime to facilitate cooperation regarding their mutual interests in the resources of the Barents Sea. In 1975 and 1976, the two countries entered into a pair of legally binding agreements dealing with Barents Sea fisheries. In 1978, they supplemented these agreements with a much less formal practical arrangement covering fishing in a segment of the Barents Sea known as the Grey Zone due to unresolved jurisdictional claims in the area. The legally binding 2010 treaty between the two countries on boundary delimitation and cooperation in the Barents Sea resolved longstanding disagreements regarding matters of maritime jurisdiction and formalized a complex of preexisting arrangements for cooperation regarding fisheries, oil and gas development, and environmental protection. The International Maritime Organization adopted voluntary guidelines for ships operating in polar waters in 2002 and upgraded them in 2009. These informal guidelines initiated a process of institutional development that led over time to agreement on the terms of a legally binding Polar Code that entered into force at the beginning of 2017 in the form of a series of amend- 


\section{Table $5.1 \quad$ Arctic governance agreements}

\begin{tabular}{|c|c|}
\hline \multicolumn{2}{|c|}{ Formal agreements } \\
\hline 1957 & Interim Convention on the Conservation of North Pacific Fur Seals \\
\hline 1973 & International Agreement on the Conservation of Polar Bears \\
\hline 1975 & $\begin{array}{l}\text { Agreement between the Government of the Kingdom of Norway and the Government } \\
\text { of the USSR on Co-operation in the Fishing Industry }\end{array}$ \\
\hline 1976 & $\begin{array}{l}\text { Agreement between the Government of the USSR and the Government of the } \\
\text { Kingdom of Norway concerning Mutual Relations in the Field of Fisheries }\end{array}$ \\
\hline 1976 & $\begin{array}{l}\text { Convention between the USA and the USSR concerning the Conservation of Migratory } \\
\text { Birds and Their Environment }\end{array}$ \\
\hline 1980 & Convention on Future Multilateral Cooperation in Northeast Atlantic Fisheries \\
\hline 1981 & Agreement on the Continental Shelf between Iceland and Jan Mayen \\
\hline 1987 & $\begin{array}{l}\text { Agreement between the Government of Canada and the Government of the United } \\
\text { States on the Conservation of the Porcupine Caribou Herd }\end{array}$ \\
\hline 1990 & Agreement between the USA and the USSR on the Maritime Boundary (not in force) \\
\hline 1992 & Convention for the Protection of the Marine Environment of the North-east Atlantic \\
\hline 1992 & North Atlantic Marine Mammal Agreement \\
\hline 1994 & $\begin{array}{l}\text { Convention on the Conservation and Management of Pollock Resources in the Central } \\
\text { Bering Sea }\end{array}$ \\
\hline 2010 & $\begin{array}{l}\text { Treaty between the Kingdom of Norway and the Russian Federation concerning } \\
\text { Maritime Delimitation and Cooperation in the Barents Sea and the Arctic Ocean }\end{array}$ \\
\hline 2011 & Agreement of Aeronautical and Maritime Search and Rescue in the Arctic \\
\hline 2013 & Agreement on Marine Oil Pollution Preparedness and Response \\
\hline $2014 / 2015$ & The International Code for Ships Operating in Polar Waters \\
\hline 2017 & Agreement on Enhancing International Arctic Science Cooperation \\
\hline 2018 & $\begin{array}{l}\text { Agreement to Prevent Unregulated High Seas Fisheries in the Central Arctic Ocean } \\
\text { (not in force) }\end{array}$ \\
\hline \multicolumn{2}{|c|}{ Informal agreements } \\
\hline 1978 & $\begin{array}{l}\text { Agreement on an Interim Practical Arrangement for Fishing in an Adjoining Area in } \\
\text { the Barents Sea }\end{array}$ \\
\hline 1988 & $\begin{array}{l}\text { Agreement between the Government of Canada and the Government of the USA on } \\
\text { Arctic Cooperation }\end{array}$ \\
\hline 1989 & $\begin{array}{l}\text { Agreement between the Government of the USA and the Government of the USSR } \\
\text { concerning Cooperation in Combatting Pollution in the Bering and Chukchi Seas in } \\
\text { Emergency Situations }\end{array}$ \\
\hline 1989 & $\begin{array}{l}\text { Agreement between the Government of the USA and the Government of the USSR } \\
\text { concerning mutual visits by inhabitants of the Bering Strait Region }\end{array}$ \\
\hline 1991 & Shared Beringian Heritage Agreement \\
\hline 1991 & Rovaniemi Declaration on the Protection of the Arctic Environment \\
\hline
\end{tabular}




\begin{tabular}{ll}
\hline 1993 & Kirkenes Declaration on Cooperation in the Barents Euro-Arctic Region \\
\hline 1996 & Ottawa Declaration on the Establishment of the Arctic Council \\
\hline 1998 onward & Biennial Arctic Council Ministerial Declarations \\
\hline $2002 / 2009$ & Guidelines for Ships Operating in Polar Waters \\
\hline 2008 & Ilulissat Declaration on the Arctic Ocean \\
\hline 2011 & US-Russia Statement on Cooperation in the Bering Strait Region \\
\hline 2013 & Russia/US Joint Statement on enhancing bilateral cooperation on fisheries \\
& $\begin{array}{l}\text { Memorandum of understanding between the Government of the USA and the } \\
\text { Government of the Russian Federation symbolically linking national parks in the Bering }\end{array}$ \\
\hline 2015 & Strait Region \\
\hline 2018 & Declaration to Prevent Unregulated Fishing in the Arctic Ocean \\
\hline
\end{tabular}

ments to the multilateral SOLAS and MARPOL Conventions. A somewhat different story arises in the case of potential fisheries in the Central Arctic Ocean. In 2015, the five Arctic coastal states issued a declaration on the prevention of unregulated fishing in the Central Arctic Ocean. Given the acknowledged status of this area as high seas, however, the Arctic states recognized the need to extend their effort to address this issue by engaging other interested states, including China, Iceland, Japan, and Korea as well as the European Union. This produced a 5+5 or 10-party legally binding Central Arctic Ocean Fisheries Agreement in 2018.

More familiar, perhaps, are the numerous informal arrangements that have arisen to address Arctic issues over the last 30 years. Particularly prominent are the Arctic Environmental Protection Strategy created under the terms of the 1991 Rovaniemi Declaration on the Protection of the Arctic Environment, the Barents Euro-Arctic Region established under the terms of the 1993 Kirkenes Declaration, and the Arctic Council launched under the provisions of the 1996 Ottawa Declaration on the Establishment of the Arctic Council (Young 1998; English 2013). Both the Barents Euro-Arctic Council and the Arctic Council hold periodic ministerial meetings that have produced additional ministerial declarations dealing with issues of common concern. But these multilateral ministerial declarations do not constitute the only type of informal mechanism states have employed to initiate and nurture international cooperation in the Arctic. A number of significant arrangements are rooted in bilateral agreements between Arctic states. Russia and the United States, for example, have institutionalized cooperative arrangements dealing with matters of common concern in Beringia, including wildlife conservation, coordinated management of protected areas, contact among Indigenous peoples living in the region, and commercial shipping (Berkman et al. 2016; Young, Berkman, and Vylegzhanin 2020). In 1988, Canada and the United States reached agree- 
ment on an informal arrangement regarding transits of the Northwest Passage by American icebreakers, without prejudicing the legal position of either party regarding larger questions concerning the status of the passage (Kirkey 1995). Norway and Russia, too, have worked out the terms of a number of agreements covering informal cooperation regarding matters of common interest in the Barents Sea that are not covered by the more formal provisions of the 2010 boundary delimitation treaty.

\section{ASSESSING THE PERFORMANCE OF ARCTIC GOVERNANCE SYSTEMS}

Assessing the performance of governance systems is a tricky business (Young 2011; Ch. 4 infra). There are few opportunities to engage in useful counterfactual analyses in this realm. It is hard to construct informed analyses regarding how things would have developed in the absence of a particular regime, such as the polar bear agreement, the Norway-Russia boundary treaty, or the Arctic Council. As the common distinction among outputs, outcomes, and impacts makes clear, moreover, there are significant differences regarding what we have in mind in asking questions about performance (Miles et al. 2002; Underdal and Young 2004). It is one thing to enquire whether the parties have succeeded in moving an agreement from paper to practice. It is another matter to ask whether the resultant regime has made a real difference in solving the problem(s) that led to its creation. Nevertheless, this does not mean we are unable to reach any significant conclusions regarding the performance of Arctic governance systems and, more specifically, gather observations that shed light on the central question regarding the validity of the common preference for formalized arrangements.

\section{Formalized Arrangements}

It is apparent, to begin with, that formalization provides no guarantee of success in efforts to create cooperative arrangements to solve problems of common concern. The polar bear agreement was a remarkable achievement, bringing together government officials and members of the science community around a shared interest in the conservation of an iconic species during Cold War times (Fikkan et al. 1993). It is reasonable to argue that the agreement legitimized the efforts of officials working in the US Fish and Wildlife Service, the Canadian Wildlife Service, and their counterparts in other signatories and provided needed support for the work of the Polar Bear Specialists Group operating under the auspices of the International Union for the Conservation of Nature (IUCN). But we can turn this argument around. It may make better sense to think of the informal cooperation among these actors as drivers of the 
process that produced the 1973 agreement than as an outcome of the regime established under the terms of the agreement. Even more important is the observation that today polar bears are increasingly threatened by the impacts of climate change on the Arctic's marine systems. The destruction of habitat resulting from the recession and thinning of sea ice attributable to climate change may turn out to be a critical determinant of the fate of this species. But there is little to be done within the context of the 1973 agreement to alleviate the effects of this growing threat.

In 1987, Canada and the United States entered into a binding agreement establishing the International Porcupine Caribou Board, a mechanism that has played a constructive role in introducing a co-management system in which representatives of user groups are accorded a significant voice in decision-making about the management of renewable resources (Kofinas 2005). Nevertheless, the size of the Porcupine caribou herd, which migrates annually across the international boundary between Alaska and Yukon, has fluctuated dramatically over the years; there is little evidence to suggest that efforts to implement the terms of the bilateral agreement have played an important role in stabilizing the population dynamics of this herd.

The central Bering Sea pollock agreement was negotiated and entered into force only in the aftermath of the crash of pollock stocks in the regime's catchment area due to intensive fishing (Dunlap 1995). There has been little evidence of a revival of pollock stocks in this area since then, despite the prohibition on harvesting imposed under the terms of the 1994 convention. There is some controversy among fisheries biologists regarding the biophysical conditions governing the status of pollock stocks in the central Bering Sea. But there is no basis for concluding this regime has solved or even alleviated the problem that led to its creation.

In the case of migratory birds, the critical problem arises from the fact that key species migrate annually over long distances and pass through multiple jurisdictions. No international agreement focused mainly on the Arctic can ensure the conservation of these species. In recent years, the Arctic Migratory Bird Initiative (AMBI), launched through the efforts of the Arctic Council's Working Group on the Conservation of Arctic Flora and Fauna, seems to be making a difference in promoting international cooperation among states located along major flyways used by migratory birds that spend the summer in the Arctic and the winter in southern latitudes. Interestingly, AMBI is a voluntary initiative operating under the auspices of an informal governance system (Barry et al. 2020). While many forces play a role in this context and future developments are difficult to forecast, there is a case to be made for the proposition that AMBI will prove more effective than efforts to implement the terms of legally binding arrangements like the 1976 agreement between the Soviet Union and the United States. 
Somewhat similar observations are relevant in thinking about the performance of the 2011, 2013, and 2017 agreements negotiated under the auspices of the Arctic Council. The 2011 agreement deals with search and rescue in the Arctic; it is a regional version of the more encompassing international Safety of Life at Sea Convention (SOLAS). While the agreement has provided some incentives for authorities in the Arctic states to upgrade their operational capabilities to address search and rescue needs, the 2011 Arctic agreement adds little of substance to the overarching SOLAS regime. Much the same is true of the 2013 marine oil spill preparedness and response agreement, which sets forth a regional version of the overarching regime established under the International Convention on Oil Pollution Preparedness, Response and Cooperation (OPRC) (Johnstone 2018). A notable feature of the 2013 Arctic agreement is that it contains no provisions dealing with oil spill prevention. Today, offshore hydrocarbon development in the Arctic is limited to a few small installations. Whether or not the 2013 agreement makes a difference in the future remains to be seen. But its achievements to date are limited. As for the 2017 agreement on the enhancement of cooperation in scientific research, these are early days. Some of its provisions may prove significant over time (Berkman et al. 2017). But it is notable that the agreement lacks substance regarding specific steps the eight Arctic states are obligated to take to promote international cooperation regarding research activities carried out within their jurisdictions or beyond the boundaries of their jurisdiction in the Central Arctic Ocean. The growth of great-power tension in the Arctic in recent years does not bode well for the operation of this agreement.

\section{Informal to Formal Arrangements}

The story regarding governance systems that begin (at least in part) as informal arrangements but evolve into formalized arrangements is different in some respects but similar in others. It seems fair to say that the 2010 Norway-Russia boundary delimitation treaty resolved once and for all a lingering dispute over jurisdiction in the Barents Sea (Henriksen and Ulfstein 2011). This is no small accomplishment. Still, it is important to note that the two countries had set up cooperative arrangements dealing with common concerns relating to the Barents Sea involving a mix of formal and informal agreements dating back to the 1970s (Stokke 2012). The relatively informal 1978 agreement, in particular, served to defuse tension in a portion of the central Barents Sea subject to overlapping jurisdictional claims. Knowledgeable analysts have generally praised the accomplishments of these bilateral arrangements, now formalized in the 2010 treaty. Most believe that this cooperation has played a significant role in the success of efforts to manage the commercial fish stocks of the Barents Sea. But it is relevant to note that the arrangements formalized 
in the 2010 treaty have important limitations when it comes to meeting challenges arising today and likely to become more serious in the future (Young, Berkman, and Vylegzhanin 2020). Cooperation between the two states has not succeeded in avoiding major challenges arising from the introduction of invasive species, such as snow crabs (Østhagen and Raspotnik 2019). Even more to the point, this bilateral agreement lacks the authority to address issues that arise when shifts in the distribution of fish stocks (e.g., cod) open up opportunities for fishers from other countries (e.g., the Faroe Islands) to harvest fish that move beyond the boundaries of Norwegian and Russian jurisdiction.

The story of efforts to govern commercial shipping in Arctic waters is, in some ways, more encouraging. Treated as a minor concern in the past due to harsh biophysical conditions, interest in the governance of Arctic shipping has risen in recent times as the volume of commercial shipping within the Arctic or passing through the Arctic has grown (Hildebrand et al. 2018). Though projections regarding such matters are hazardous, it is not unreasonable to expect commercial shipping in the region to continue to grow during the foreseeable future. Interest in this issue became manifest during the $1990 \mathrm{~s}$, and the $2002 / 2009$ voluntary guidelines served to put the issue on the map as a suitable topic for the development of a governance system. The 2009 report (including specific recommendations) of the Arctic Marine Shipping Assessment, an informal activity carried out under the auspices of the Arctic Council, served to heighten interest in this issue among members of the policy community substantially. This set the stage for the negotiation of the principal elements of the Polar Code under the auspices of the International Maritime Organization, including an assemblage of Arctic-specific provisions relating to safety of life at sea and environmental protection. Though some have criticized the Polar Code for its failure to include provisions dealing with matters like heavy fuel oils, black carbon, injury to marine mammals, noise pollution, and the control of invasive species, the code has teeth regarding the matters it does cover. It mobilizes actors like the International Association of Classification Societies and marine insurers to demand compliance with requirements regarding matters such as the possession of an up-to-date Polar Certificate. And the entry into force of the Polar Code has energized those demanding even stronger provisions governing commercial shipping in the Arctic. The odds are good at this stage, for example, that restrictions regarding the combustion and carriage of heavy fuel oils will be added to the Polar Code in the coming years. Although the results fall well short of perfection in the eyes of those seeking to impose stricter regulation on Arctic shipping, they are far from trivial.

The case of commercial fishing in the Central Arctic Ocean presents a very different picture (Vylegzhanin et al. 2020). There are no commercially significant fish stocks located in the area covered by the agreement today. In fact, the reigning view among fisheries biologists is one of skepticism regarding 
the likelihood that significant fish stocks will emerge in this area any time soon. It is likely, therefore, that the provisions of the agreement will not be tested severely during the foreseeable future. Proponents of the arrangement take the view that the negotiation of the agreement nevertheless constitutes a significant achievement. It is precedent-setting in the sense that it is one of the first arrangements relating to marine resources in which the relevant parties have put in place a regime before the commencement of commercial exploitation of natural resources rather than struggling to impose some sort of order once exploitation is under way. And the regime created under the terms of the agreement establishes the precautionary principle as one of its central elements. It is possible that we may look back at some future time and see these as important achievements. At the moment, however, all we can do is to note these elements of the regime and treat them as features to keep in mind when it comes to assessing the performance of the regime over time.

\section{Informal Arrangements}

As noted, a prominent feature of recent practice regarding the creation and operation of Arctic governance systems is the prominent role accorded to arrangements that are informal in the sense that they are not grounded in legally binding instruments. A number of informal bilateral agreements dealing with concrete issues of concern to a pair of Arctic states have produced positive results. The 1988 agreement on transits of the Northwest Passage has served to avoid friction between Canada and the United States regarding the use of the passage, though it is fundamentally an agreement to disagree on the legal status of the passage (Kirkey 1995). Interestingly, Russia and the United States have entered into a number of bilateral agreements dealing with Arctic issues of interest to the two countries, even as tensions of a more geopolitical nature have risen (Berkman et al. 2016). The authorities in each country responsible for managing protected lands have taken a number of informal steps to twin national parks on the two sides of the Bering Strait Region. There is a bilateral agreement to join forces to protect polar bears using the waters of Beringia. Russia and the United States worked out a vessel routing scheme for the Bering Strait, which they then proceeded to take to the International Maritime Organization for endorsement as an element in the broader regime for Arctic shipping (Young, Berkman, and Vylegzhanin 2020).

The central focus of attention in the realm of informal agreements, however, is the creation and operation of multilateral arrangements established under the provisions of ministerial declarations. Among these, it is worth devoting particular attention to the Barents Euro-Arctic Region (BEAR), an arrangement designed to promote regional cooperation on a range of functional concerns among the northern counties of Fennoscandia and their counterparts in north- 
western Russia, and the Arctic Council (AC), a high-level forum created and operated by the eight Arctic states to address issues of environmental protection and sustainable development on a circumpolar basis.

Perhaps the most striking feature of the BEAR is that it allows the parties to cooperate simultaneously on two levels through the activities of the intergovernmental Barents Euro-Arctic Council and the Regional Council in which the principal participants are representatives of subnational governments (Dellenbrant and Olsson 1994). The importance accorded to this dual structure may well explain why the parties to the 1993 Kirkenes Declaration chose to avoid the use of an international legally binding instrument in establishing the BEAR (Young 1998). In practice, the BEAR has spawned a sizable collection of pragmatic efforts at the regional level to encourage cooperation dealing with a range of issues relating to health, education and welfare, environmental protection, the concerns of Indigenous peoples, and cultural traditions. It is not feasible to construct a box score summarizing the performance of the BEAR over several decades regarding each of these functional areas. Nevertheless, it is reasonable to say that this arrangement has fostered a variety of programmatic initiatives producing results that are generally beneficial, though they are not showy.

It is a stretch to assert, as the foreign ministers of the eight Arctic states did in 2013, that "the Arctic Council has become the pre-eminent high-level forum of the Arctic region and we have made this region into an area of unique international cooperation" (Kiruna Declaration 2013). Still, there is a sense that the council has accomplished a good deal over the years since its establishment in 1996 under the terms of the Ottawa Declaration (Smieszek 2019). How can we explain this record, given the facts that the council lacks the authority to make binding decisions and that the material resources under its control are negligible? The answer to this question lies in the efforts of the AC's Working Groups, Task Forces, and Expert Groups to exercise influence through processes involving agenda-setting, information dissemination, and the coordination of informal programs. The Arctic Monitoring and Assessment Programme, one of the council's working groups, has assembled the data needed to put a number of environmental concerns (e.g., persistent organic pollutants, heavy metals, radioactive contamination) on the policy agenda and helped to energize efforts leading to international agreement on measures like the 2001 Stockholm Convention on Persistent Organic Pollutants (Downie and Fenge 2003; Stone 2015). The Working Group on the Conservation of Arctic Flora and Fauna has documented areas of high-level concern, produced an influential Arctic Biodiversity Assessment, and helped to coordinate the work of coalitions of the willing to make progress in areas like the protection of migratory birds (Barry et al. 2020). The terms of the 2011, 2013, and 2017 legally binding agreements have all been hammered out through the 
efforts of issue-specific Task Forces of the Arctic Council, though the council itself lacks the authority to adopt such agreements. The 2004 Arctic Climate Impact Assessment documented the extraordinary effects of climate change in the Arctic, energizing enhanced global efforts to deal with climate change through mechanisms like the UN Framework Convention on Climate Change (Arctic Climate Impact Assessment 2005). The 2009 Arctic Marine Shipping Assessment, which was conducted by the Working Group on the Protection of the Arctic Marine Environment and included a set of actionable recommendations, clearly played a role in propelling the process within the International Maritime Organization resulting in agreement on the provisions of the Polar Code in 2014/2015 (Hildebrand et al. 2018). Critics tend to downplay or even dismiss these forms of influence, noting that the Arctic Council lacks the authority and the resources to undertake forceful initiatives to solve problems on its own. Taken together, however, these modest forms of influence add up to an overall record of performance on the part of the council that compares favorably with the achievements of the more formalized governance systems created to address various problems over the last several decades.

\section{ARCTIC GOVERNANCE IN A BROADER CONTEXT}

What can we conclude from this overview of the performance of Arctic governance systems? Needless to say, it is important to proceed with caution in responding to this question. There are few opportunities to engage in natural experiments, comparing the performance of formalized arrangements and informal arrangements dealing with the same problem or even distinct problems that resemble each other in relevant ways. Still, the available evidence suggests, at least in the case of the Arctic, that formalized arrangements are not generally preferable in terms of effectiveness and that informal arrangements are not simply underdeveloped governance systems that should be nurtured to become more formalized arrangements at the first opportunity. All three types of arrangements reviewed in the preceding section have yielded positive results under some conditions but led to modest accomplishments or even failure under others. What this suggests is that it is a mistake to focus too much attention on the issue of formalization in thinking about the design of governance systems. This does not mean that the question of whether or not to ground an agreement in a legally binding instrument is irrelevant. But it does mean that we should be paying equal attention to a variety of other diagnostic conditions in crafting the terms of governance systems and taking the necessary steps to move them from paper to practice once we reach agreement on their substantive provisions. 
The preceding discussion addresses the performance of Arctic governance systems treated largely as self-contained arrangements. But it is important to recognize that we are witnessing the evolution of an Arctic governance complex in the sense of an expanding collection of distinct elements that interact in a variety of ways but do not stand in any hierarchical relationship to one another (Young 2012). As recent research on international governance suggests, combinations of this sort are common; any effort to evaluate the performance of specific governance systems must take into account the links between individual arrangements and the larger complexes to which they belong. An initial, perhaps surprising, observation about this phenomenon is that there are cases in which interactions of this sort produce synergy rather than leading to crippling interference on the part of overlapping or intersecting arrangements. But there is nothing automatic about the occurrence of positive interactions (Oberthür and Gehring 2006).

A natural question, then, is whether the performance of specific regimes can be enhanced by taking steps to improve coordination among the elements of the institutional complexes within which they operate (Oberthür and Stokke 2011)? The expanding Arctic governance complex encompasses elements that differ in a number of important respects: some are bilateral, others are multilateral; some are formal, others are informal; some are restricted to Arctic states, others include non-Arctic states; some address a single issue, others have a broader mandate. What mechanisms are available to address the issue of coordination in such a setting? In the case of the Arctic, two plausible answers have emerged, one calling for the negotiation of a constitutive Arctic Treaty; the other suggesting that an informal mechanism like the Arctic Council can play this role. Is either of these answers satisfactory? In my judgment, while the need for coordination among the elements of the Arctic governance complex is rising, neither of these options provides the basis for a workable solution. An important challenge going forward, therefore, will center on the effort to devise an innovative response to the challenge of improving coordination among the elements of the Arctic governance complex.

Constitutive arrangements provide broad frameworks that can serve as foundations on which to build operational regimes dealing with more specific needs for governance. A prominent case in point is the 1982 UN Convention on the Law of the Sea, which not only provides a basis for the development of a series of implementing agreements but also offers general principles regarding matters like jurisdiction and the roles of coastal, flag, and port states that guide the development of separate regimes dealing with fishing, shipping, protected areas, and so forth. Closer to home for those interested in the Arctic is the 1959 Antarctic Treaty (Dodds et al. 2017). This constitutive agreement calls for freezing the jurisdictional claims of individual states, demilitarizing and denuclearizing the continent, ensuring that Antarctica is used exclusively 
for peaceful purposes, and guaranteeing open access for representatives of the parties to all parts of the treaty area. Over the years, a number of operational arrangements dealing with matters like the conservation of seals, fishing, and environmental protection on and around the continent have developed within this constitutive framework.

Is a parallel Arctic Treaty a realistic option? The answer to this question is no, at least during the foreseeable future (Young 2011). The terrestrial portions of the Arctic lie firmly within the jurisdiction of the Arctic states. The Arctic coastal states have asserted their competence to take the lead in addressing issues relating to the Arctic Ocean; they argue that no new framework agreement is needed to deal with marine issues in the Arctic. At the same time, non-Arctic states have legitimate interests in the Arctic, and they are taking steps to ramp up activities, including both economic initiatives and scientific programs, that are making it impossible to ignore their role as significant stakeholders in Arctic affairs. The Arctic is and will continue to be a theater of operations for advanced military systems, including nuclear-powered submarines carrying state-of-the-art strategic weapons. The Antarctic Treaty was the product of a unique combination of circumstances in which the superpowers of the time (the Soviet Union and the United States) joined forces to strike a bargain with the so-called claimant states to exempt the continent and its surrounding waters from the impacts of political competition by agreeing to treat the area as an international space dedicated to peaceful uses (Berkman et al. 2011). While it is always hazardous to make firm predictions regarding the future in an area like this, no such opportunity to strike a bargain on the terms of a constitutive treaty for the Arctic is on the horizon at this time.

Under the circumstances, numerous commentators have advanced proposals for reforming the Arctic Council to provide it with the capacity to play a coordinating role in the context of the expanding Arctic governance complex (Smieszek 2019). Is such a role for the council a realistic prospect? Three factors seem critical in this context. To perform this role effectively, the council would have to find ways to (i) allow non-Arctic states to engage more fully in its work, (ii) acquire the authority needed to underpin coherent coordinating efforts, and (iii) gain access to more substantial material resources. The fact that the council's constitutive features are articulated in the provisions of a ministerial declaration means that it would not be hard to introduce changes regarding such matters in the event that the relevant actors were able to agree on the nature of the required adjustments. But this is where the problem arises. It is apparent that there is little prospect of agreement concerning such matters during the foreseeable future. There is nothing approaching consensus regarding the proper way to delineate the roles of Arctic and non-Arctic states when it comes to addressing Arctic issues going forward. In any case, providing the Arctic Council with actual authority regarding specific matters would be 
difficult to accomplish using the mechanism of a ministerial declaration; such an effort might well trigger a need to reach agreement on the terms of a legally binding instrument, raising once again the issues identified before. No realistic source of material resources that the council could use to perform an expanded coordinating role is in sight. This does not mean that there is no role for the Arctic Council as a coordinator of the Arctic governance complex. But it is important to bear in mind the limits of the capacity of the council to play such a role.

The need for a coordinator of the Arctic governance complex is growing, but neither of the standard responses seems likely to offer an effective way forward regarding this concern during the foreseeable future. So, what is to be done? There is no straightforward, much less simple, answer to this question. But one avenue that may be worth exploring in some detail centers on the articulation of a set of principles that provide the basis for social practices among those interested in the Arctic, even though they are not embedded in any formalized arrangement. The precautionary principle, which suggests proceeding with care when it comes to potentially disruptive activities, might offer a place to start (Vylegzhanin et al. 2020). The idea of stewardship, which calls for systemic thinking not limited to considerations easily expressed through calculations of costs and benefits, is appealing in this context (Chapin et al. 2015). The value of making use of different types of knowledge, including Indigenous knowledge, is another important consideration. Obviously, these are early days regarding such matters; other elements would need to be added in an effort to assemble a normatively grounded, coherent, and widely shared package of operating principles that could develop into a constitutive foundation for the growing collection of operational arrangements included in the Arctic governance complex. The outcome of this process might well become an important determinant of the performance of the individual elements of the Arctic governance complex. Interestingly, there is no reason to assume that formalization would constitute a necessary condition for such a package of operating principles to make a difference in coordinating the Arctic governance complex going forward. 